\title{
مخالفات في ميراث العصبات وأثرثها على الأمن الاجتماعي
}

Irregularities in the neurons of inheritance and their impact on social security مكتورة/ زينب أحمد السميد محهد

أستاذ مساعد بكلية الآداب و العلوم بو ادي الدواسر جامعة سطام بن عبد العزيز

و المدرس بكلية الاراسات الإسلامية والعربية للبنات بالمنصورة جامعة الأزهر

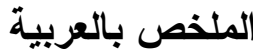

يعد فقه الفر ائض و المواريث من أهم العلوم الثرعية، وقد زاده الله تثريفا

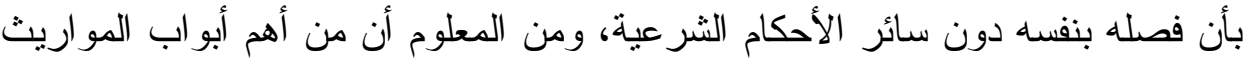

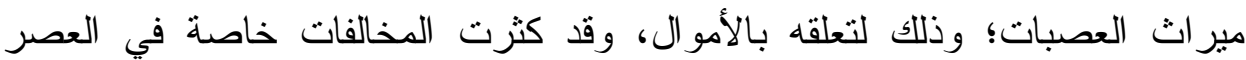
الحديث؛ لذا خصصت هذا البحث لمير اث العصبات، ومحاولة حصر أثنهر المخالفات فئن

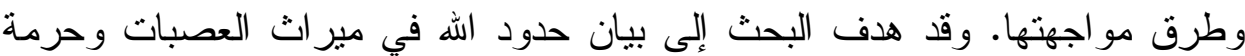
مخالفتها، واستخدم الباحثة الهنهج الاستقر ائي و الاستتباطي، وكان الهان من أهم النتائج التي

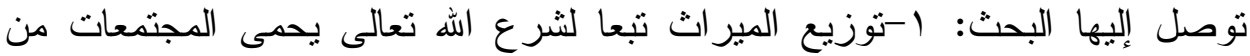

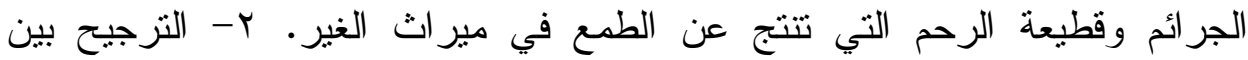
العصبات يكون بالجهة أو الدرجة أو بقرب القرابة، ويكون ذللك بين الأخوة ولأعمام.

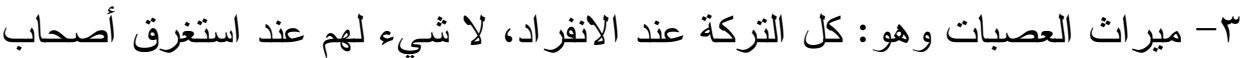

$$
\begin{aligned}
& \text { الفروض التركات، الباقي بعد أصحاب الفروض. } \\
& \text { الكلمات الافتتاحية: مخالفة - عصبة - مير اث - أمن - مجتمع التع }
\end{aligned}
$$




\section{The summary in Arabic}

One of the most important legal sciences is the jurisprudence of religious duties and inheritance, and God has honored it by honoring it by separating it by itself without the rest of the legal rulings, and it is known that one of the most important chapters of inheritance is the inheritance of gangs because of its attachment to money, and violations have increased, especially in the modern era. And methods of confronting them, and the research aimed to clarify the limits of God in the inheritance of gangs and the sanctity of violating them, and there searcher's use of the inductive and deductive approach, and one of the most important findings of the researcher.) - The distribution of inheritance according to the law of God Almighty protects societies from crimes and kinship that results from greed for the inheritance of others. - The weighting between the gangs is by the side, the degree, or close kinship and that is between the brothers and the uncles - The inheritance of the gangs is: the whole estate when it is alone, nothing is for them 


\section{المقدمة}

الحمد لله و الصلاة و السلام على رسول الله، وعلى آله وصحبه أجمعين. وبعد:

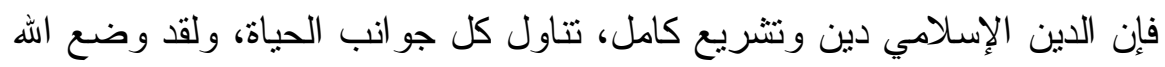

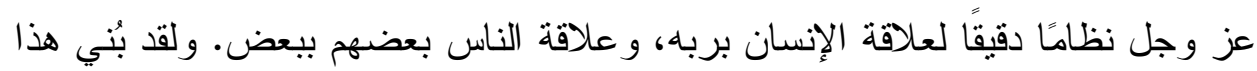
النظام على أسس سليمة. و إن كان رقي الأمم يقاس -في العصر الحالي- بمدى تطبيقها لوثيقة حقوق

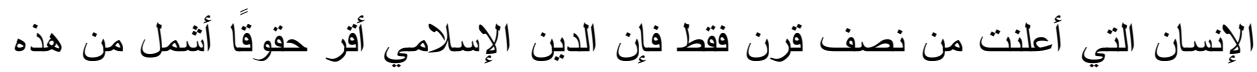

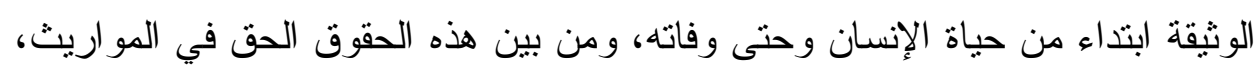

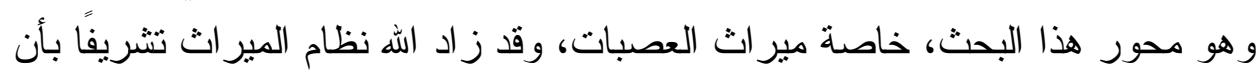

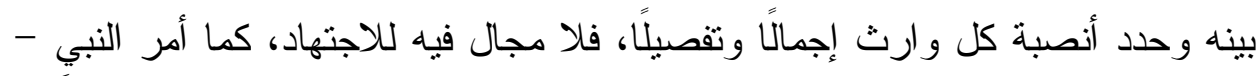
صلى الله عليه وسلم - بتعليم الفرائض وتعليمها، فقال -صلى الله عليه وسلمَ- : (تعلَّمو ا

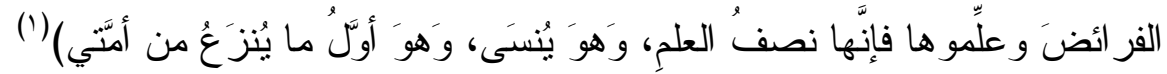

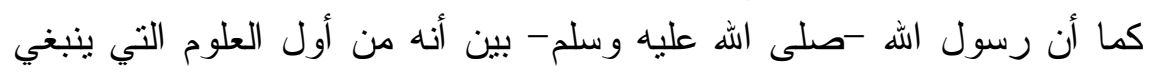

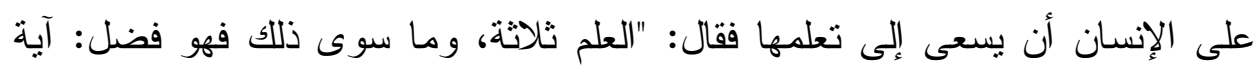

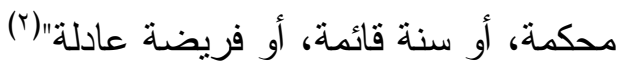

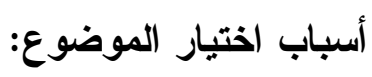
أولًا: أسباب ذاتية: أبناب: 1- رغبتي الذاتية في اختيار علم المواريث و البحث فيه. r- اهتمامي بقضايا الساعة التي تشغل الر أبي العام.

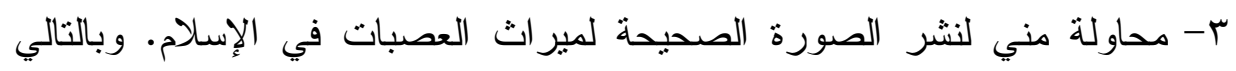
نشر الصورة الصحيحة للإسلام. ثانيًا: أسباب موضوعية: 1 - تقسيم كثير من الناس المواريث موصدئ على حسب أهو ائهم. r- بيان مدى خطورة هذا العلم، وبيان حرمة التلاعب بهن. 
أهمية الموضوع:

$$
\begin{aligned}
& \text { ا - يعد أول بحث في مير اث العصبات -حسب علم الباحثة-. }
\end{aligned}
$$

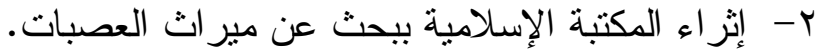

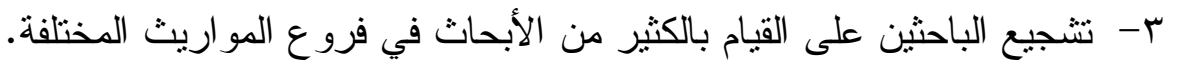

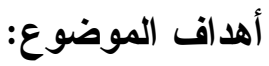

يهدف البحث إلى تحقيق جملة أهداف أهمها:

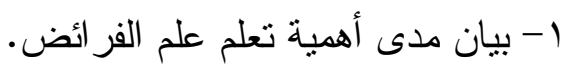

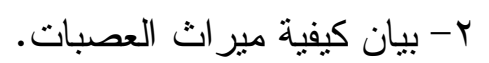

الدر اسات السابقة:

قد تطرق لعلم المواريث كثير من العلماء قديمًا وحديثًا، لكنى خصصت هذات

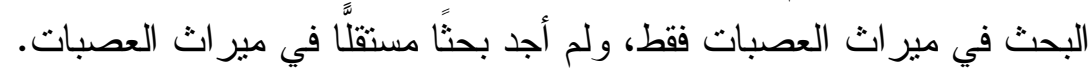

إثكالية الموضوع:

مخالفات في ميراث العصبات، خاصة بعد انتشار بعض العادات السيئة التي

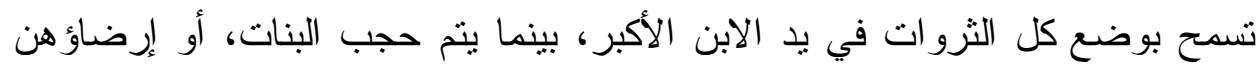

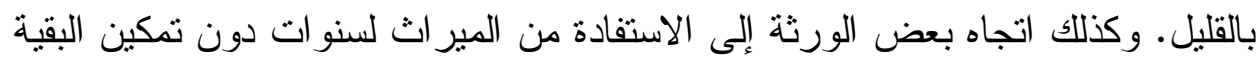

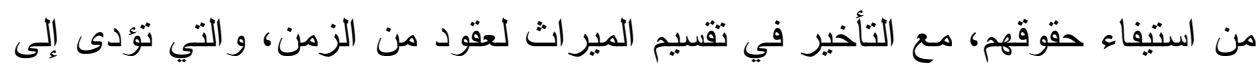

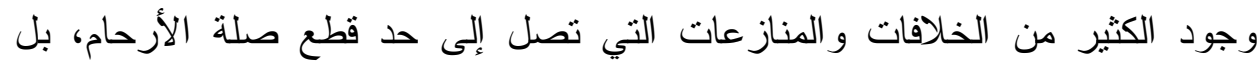
يتطور الأمر في بعض الحالات من إلى جر ائم القتل.

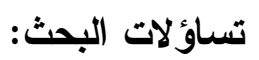

ويمكن من خلال ذلك أن نضع الكثير من التساؤلات، ومنها:

1 - هل نصوص المير اث قابلة للتعديل؟

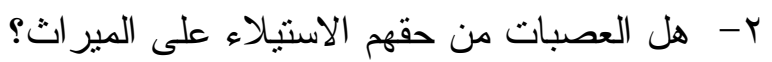

r- كيف نو اجه هذه المخالفات؟

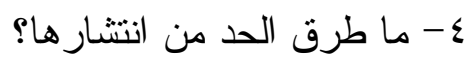

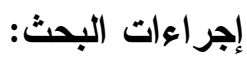

ا- عزو الآيات القر آنية، وذلك بذكر السورة ورقم الآية في المتن.

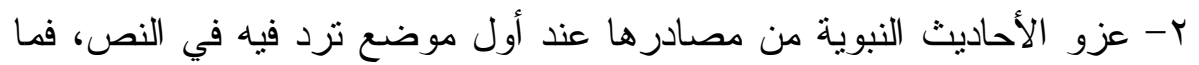

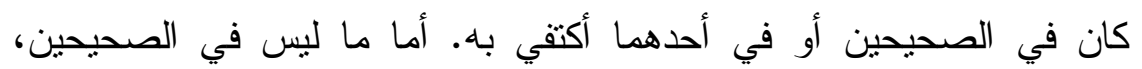

فأورد أقو ال المحدثين في تصحيحه، أو تضعيفه أو ذكر درجته، فأذكر المؤلف 
ثم اسم الكتاب، ثم الكتاب و الباب الذي ورد فيه الحديث، ثم ذكر رقم الحديث و الجزء و والصفحة.

r- استعمال الرموز كاختصـار الكلمات التالية:

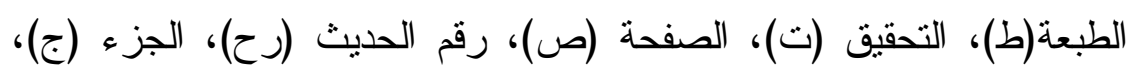

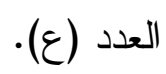

ع - تهميش الكتب و الرسائل العلمية و المقالات كالتالي:

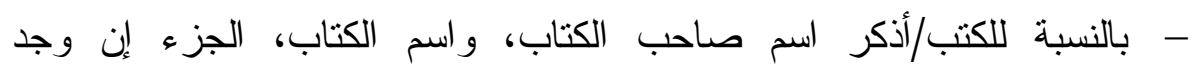

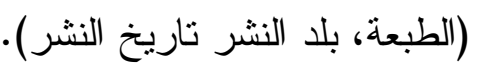

- - الرسائل العلمية: اسم صاحب الرسالة، و عنو انها، و واسم الجامعة، و الصفحة. - - المقالات: ذكر صاحب المقال، و عنو انه، ور ابط الموقع.

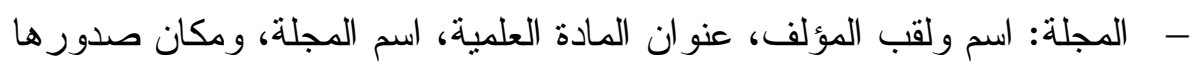
العدد ورقم الصفحة.

- منهج البحث: اعتمدت في البحث على المنهج الاستقر ائي الاستتباطي في جمع المادة العلمية. هيكلية الار استة:

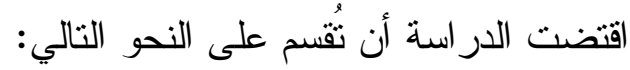
الفصل التمهيدي: أقسام الإرث وأحوال العصبات.

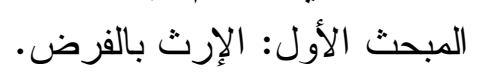

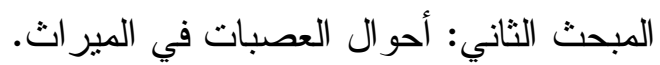
الفصل الأول: ميراث العصبات.

المبحث الأول: تعريف العصبة، و أدلة توريثهم.

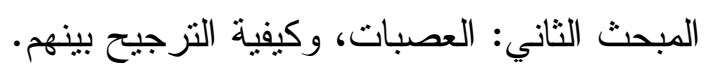
الفصل الثاني: مخالفات في ميراث العصبات وأثره على الأمن الاجتماعي.

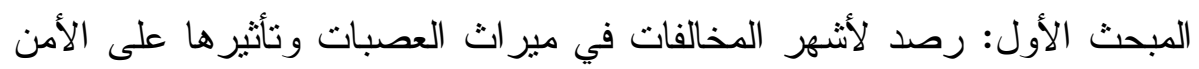
الاجتماعي. المبحث الثاني: علاج هذه المخالفات وكيفية مو اجنها. 


\section{الفصل التمهيدي \\ حول الإرث بالفرض المهاب}

في الفصل التمهيدي اقتصرت على بيان أصحاب الفروض وشروط إرثهم؛ وذلك حتى بلى يحصل ربط بين أصحاب الفرض ومعرفة حدود إرثهم و العصبات وكيفية مير اثهم.

المبحث الأول: الإرث بالفرض بط (1)

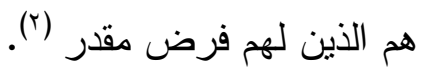

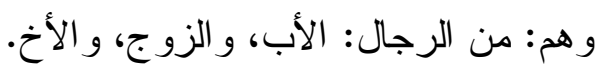

ومن النساء: البنت، بنت الابن، الأم. و الأخت الثنقيقة، والأخت والأت لأب، والأخت

$$
\text { وأو لام: المستحقون للنصف وآَ): }
$$

1- البنت بشرطين: الأول: أن تكون واحدة. و الثاني: عدم وجود أخ معصب. r- بنت الابن بثلاثة شروط الأول: عدم وجود البنت الصلبية. الثاني: أن تكون التون

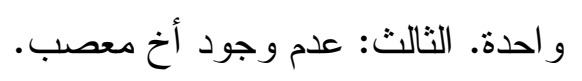

ب- الأخت الثقيقة: لها النصف بثلاثة شروط: الأول: أن تكون واحدة. الثاني:

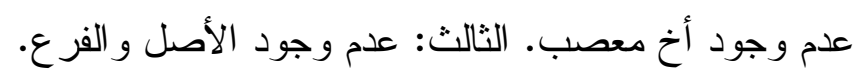

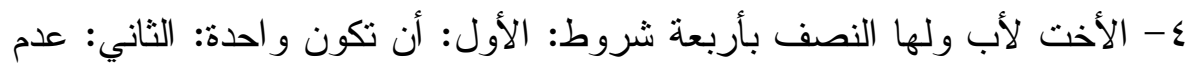

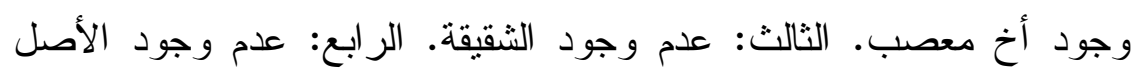

$$
\text { و الفرع. }
$$

دليل فرض النصف في ثلاثة مو اضع من القر آن،

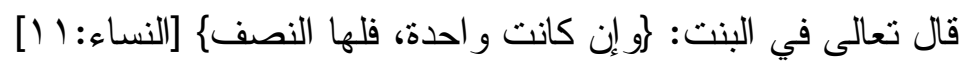


وقال تعالى في الزوج: كولكم نصف ما ترك أزواجكم إن لم يكن لهن ولدأ

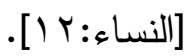

وقال تعالى في الأخت الثقيقة أو لأب: (يستفتونك، قل: الله يفتيكم في الكالدة، إن امرؤ هلك، ليس له ولد، وله أخت فلها نصف ما تركي [النساء:1V7]

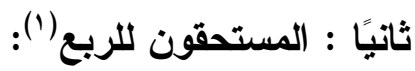

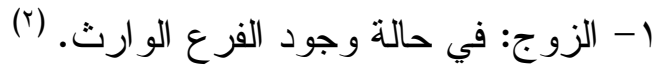

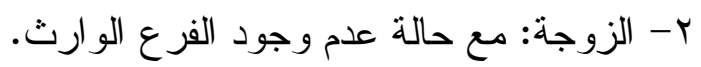

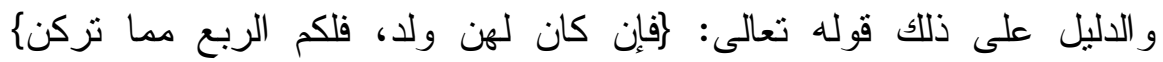

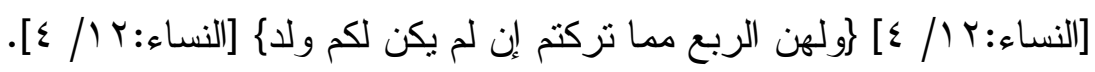
ثالثا: المستحقون للثمن: الزوجة أو الزوجات في حالة وجود الفرع الو ارث؛ لقوله تعالى: [فإن كان لكم

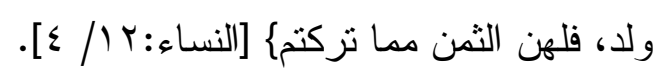
رابعا: المستحقون للثثلثين (")

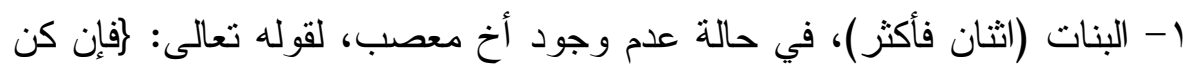

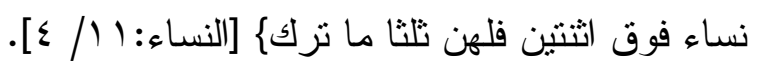

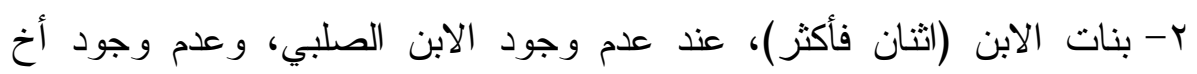
معصب، و عدم وجود البنات الصلبية.

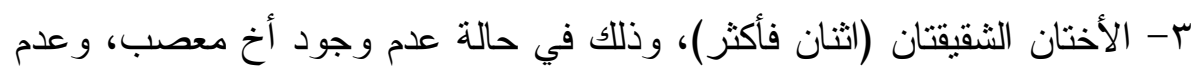

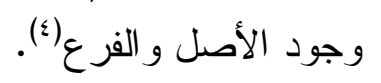

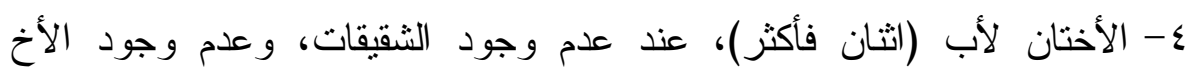

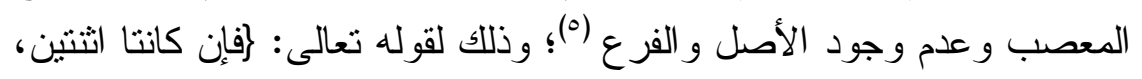

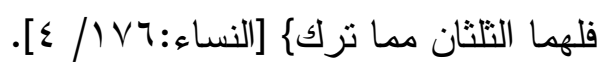




\section{خامسا: المستحقون للثلث(•):}

1- الأم في حالة عدم وجود الفرع الوارث، و عدم وجود عدد من الأخوة.

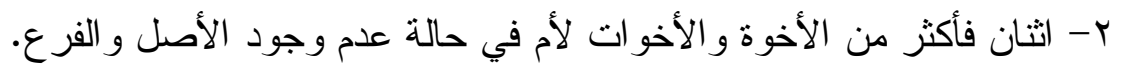
ودليل التلث للأم قوله تعالى: ، النساء: (1)

دليل استحقاق الأخوة لأم للتلث قوله تعالى: إفإن كانو أكثر من ذلك فهم شركاء

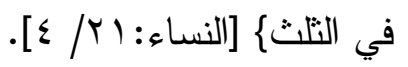
وتلثث الباقي للأم في المسألنين العمريتين، وهما وجود أحد الزوجين مع الأبوين. وذللك على النحو التالي: 1-الزوج، و والأب، و الأم.

للزوج النصف، وللأم تلث الباقي بعد نصيب الزوج، وللأب الباقي عصبة. r-الزوجة، الأب، الأم.

للزوجة الربع، وللأم تلث الباقي بعد نصيب الزوجة، وللأب الباقي عصبة ('). سادسا: المستحقون للسدس (ץ) 1- الأب: في حالة وجود الابن؛ لقوله تعالى: كو لأبويه لكل واحد منهما السدس

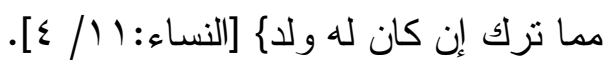
r- الجد: في حالة عدم وجود الأب و الابن.

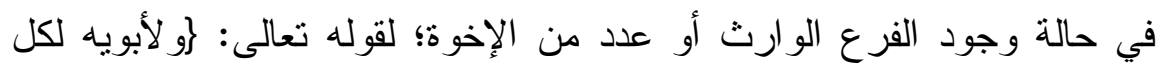

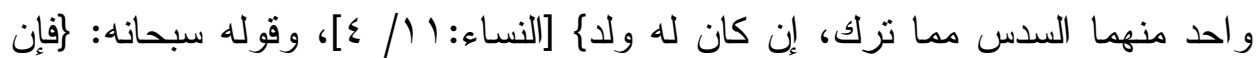

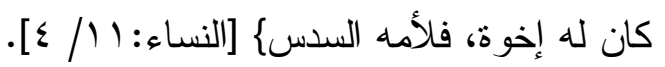
r- الجدة الصحيحة، عند عدم وجود الأم (أم الأم أو أم الأب).

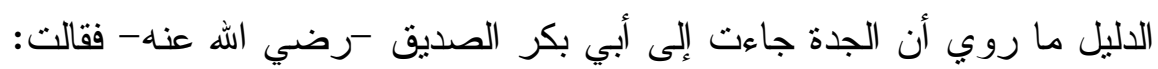
》أعطني مير اث ولد ابنتي《، فقال: 》اصبري حتى أثناور أصحابي، فاني لم أجد للك في

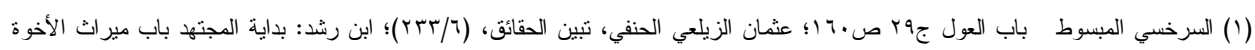

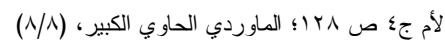

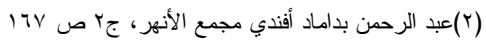

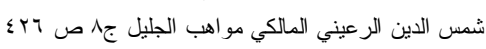

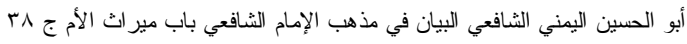

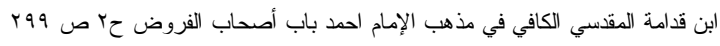




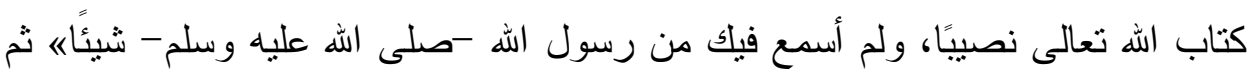

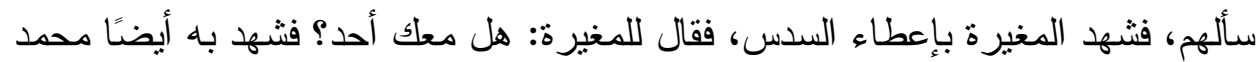

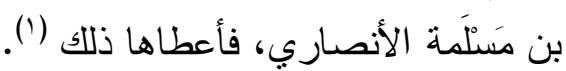

ع - بنت الابن في حالة وجود بنت صلبية واحدة، وعدم وجود ألخ الخ معصب.

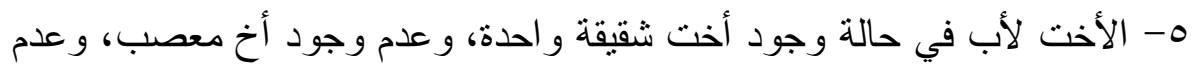

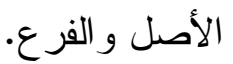

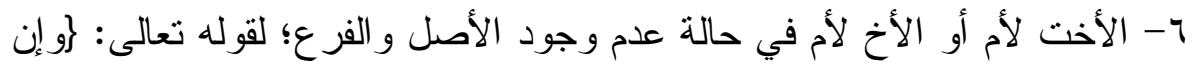

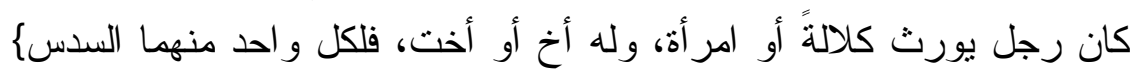

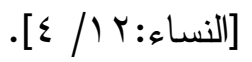




\section{الفصل الأول}

مير اث العصبات

وهو يشتمل على ثلاثة مباحث.

المبحث الأول: تعريف العصبة، و أدلة توريثهم.

وفيه مطلبان:

المطلب الأول: تعريف العصبة.

المطلب الثاني: و أدلة توريثهم.

المبحث الثاني: العصبات، وكيفية الترجيح بينهم.

وفيه مطلبان:

المطلب الأول: أنو اع العصبات.

المطلب الثاني: الفرق بين العصبة بالغير و العصبة مع الغير •

في هذا الفصل تناولت تعريف العصبات، وكيفية مير اثهم، و أدلة مير اثهم، وكيفية

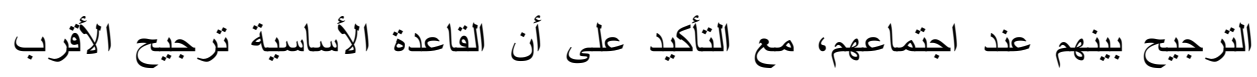

فالأقرب.

المبحث الأول: تعريف العصبة وأدلة توريثهم.

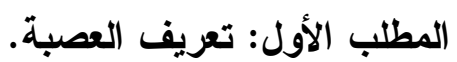

العصبة لغة: جمع عاصب، من عصب القوم بفلان، إذا أحاطو ا به (').

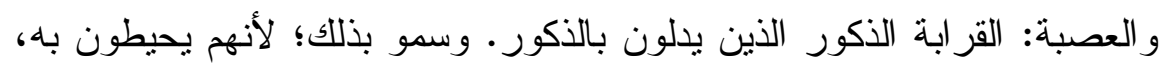

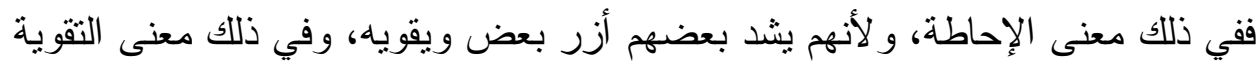
و الثد (r) (ب).

المطلب الثاني: دليل ميراث العصبات.

الدليل من القر آن الكريم:

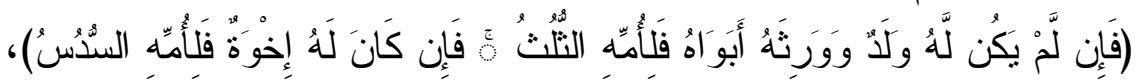

ووجه الاستدلال أن الله تعالى ذكر نصيب الأم، ولم يصرح بنصيب الآب؛ مما يدل على أنه يأخذ الباقي عصبة. 
r- من السنة قول عبد الله بن عباس كرضي الله عنهما- عن رسول الله -صلى الله

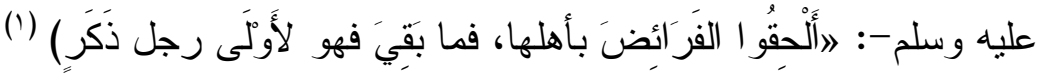

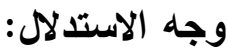

الحديث صريح الدلالة على وجوب إعطاء أصحاب الفروض فروضهم، و الباقي

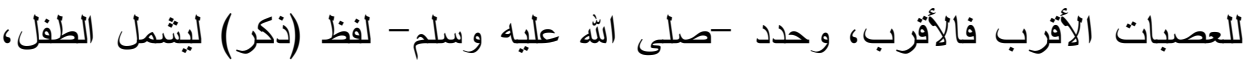
ولو كان رضيعاب(r). المبحث الثاني: العصبات وكيفية الترجيح بينهم.

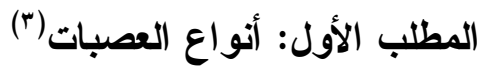

\section{1- العصب بالنفس:كل ذكر لا يدخل في نسبه للميي أثثى.}

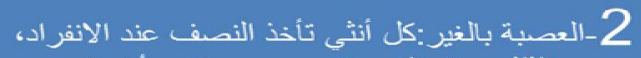

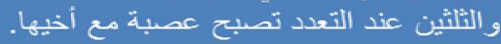

\section{3-3 العصبة مع الغير: الاخخوات مع الينات.}

الفرع الأول: أقسام العصبة بالنفس.

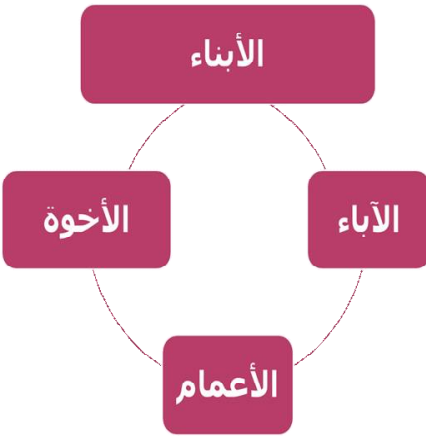

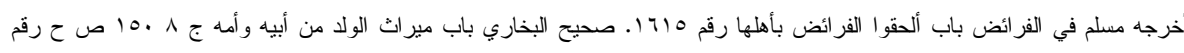

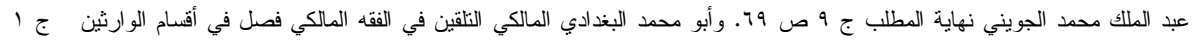

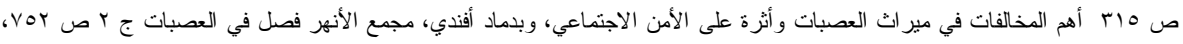




$$
\text { برث بالتعصيب أربع جهات. }
$$

1 - جهة البنوة: وتشمل الابن، و ابن الابن و إن نزل

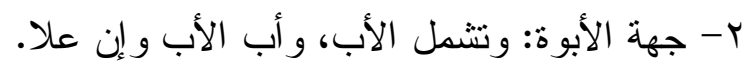

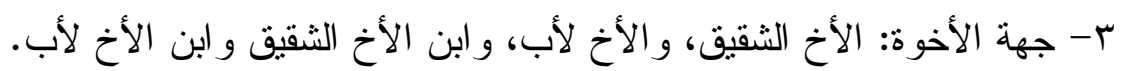

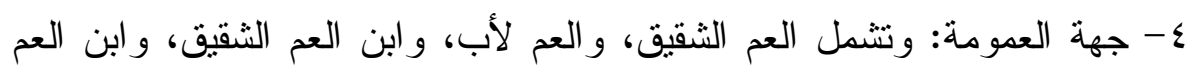

$$
\text { لأب(') (1) }
$$

الفرع الثاني: كيفية مير اث العصبة بالنفس (r)

\section{الحالة الأولي}

الحالة الثانية

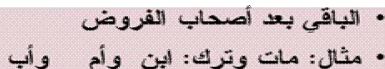

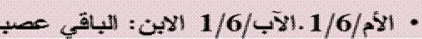

$$
\begin{aligned}
& \text { • كل التركة عثد الاحقراث }
\end{aligned}
$$

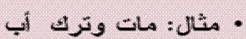

الفرع الثالث: كيفية الترجيح بين العصبة بالنفس ().

\section{الترجيع بالجهة}

\section{بالترجيج \\ بالقرابائة}

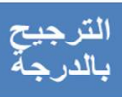

و التزجيح بينهما بالجهة: إذا كانو ا جهات مختلفة. و الدرجة: إذا كانو ا جهة و احدة.

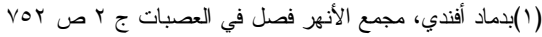

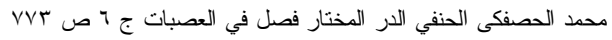

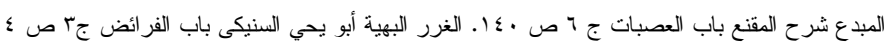

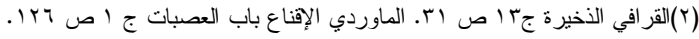

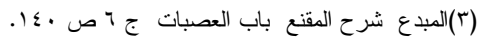


وبقرب الدرجة: وذللك يكون بين الأخوة و لأعمام (')

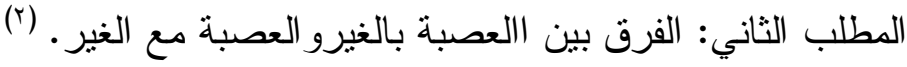

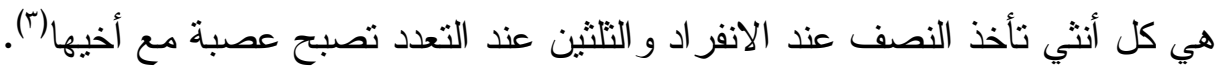

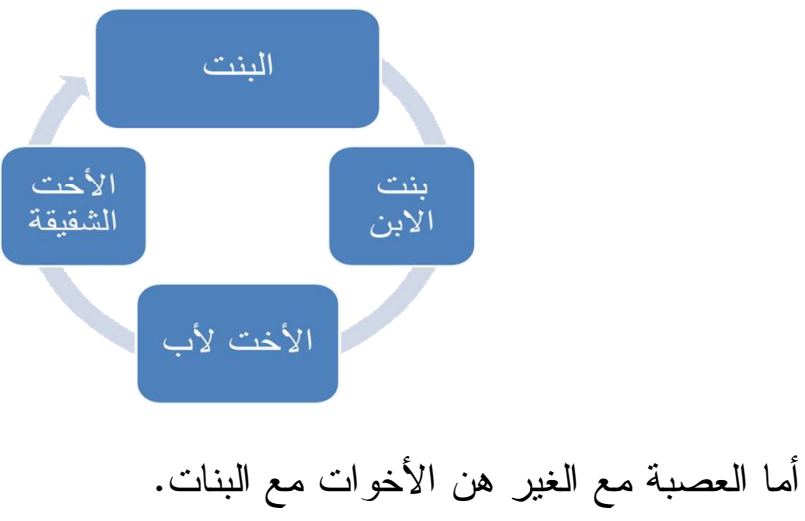




\section{الفصل الثاني}

مخالفات في ميراث العصبات، وأثره على الأمن الاجتماعي.

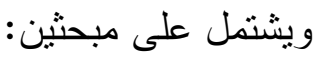

المبحث الأول: رصد لأشهر المخالفات في مير اث العصبات، وتأثنرها على الأمن الاجتماعي.

المبحث الثاني: علاج هذه المخالفات وكيفية مو اجنتها.

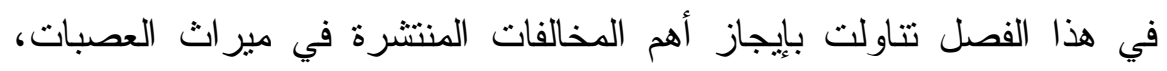

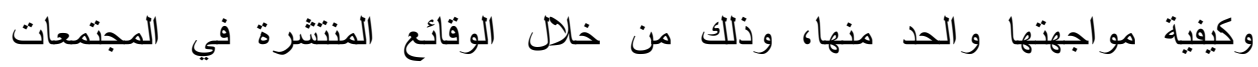
الإسلامية.

المبحث الأول: رصد لأشهر المخالفات في ميراث العصبات، وأثرها على الأمن الاجتماعي. - أو لا: تهديد العصبات للمرأة بالتتازل عن نصيبها من الميراث، إمّا عن طريق

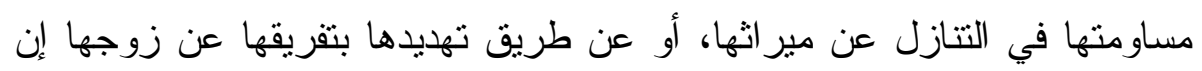

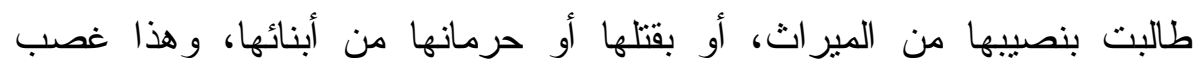

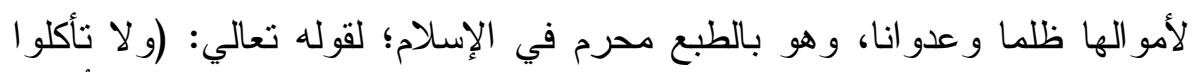

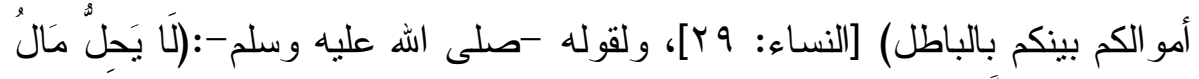

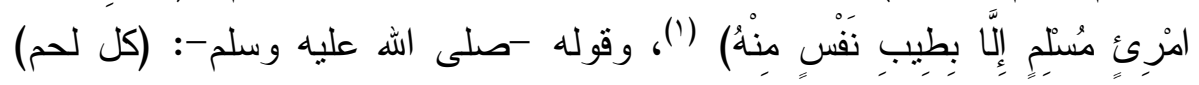
وفي رواية كلٍ جسد (نبت من حرام)، وفي رواية من سحت (فالنار أولى به)، هذا

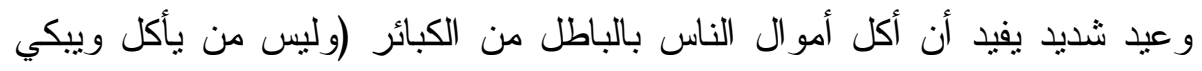

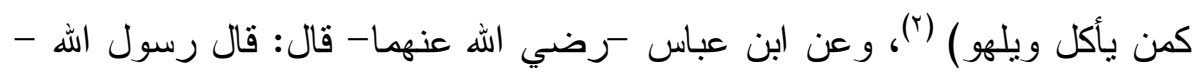

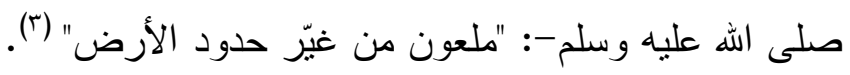
عن أبي أمامة أن رسول الله -صلى الله عليه وسلم- قال: (من اقتطع حق امرئِ مسلم بيمينه حرم اله عليه الجنة، وأوجب له النار . قالو ا: وإن كان شيئًا يسيرًا ياً

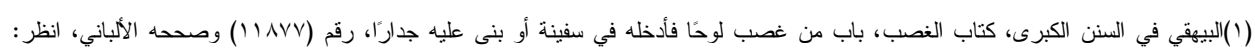

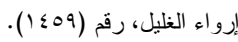

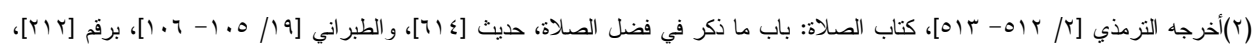
كلاهما من طريق طارق بن شهاب عن كعب بن عجرة فذكره.

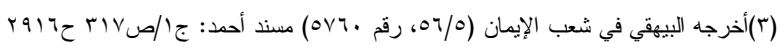

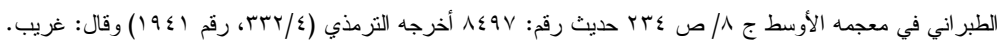


رسول الله؟ قال: وإن كان قضيبًا من أر الك، وإن كان قضيبًا من أراك، وإن كان

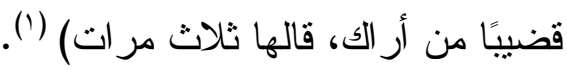

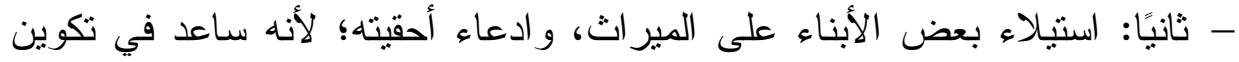

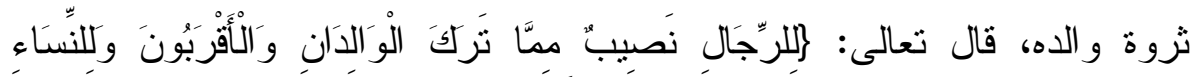

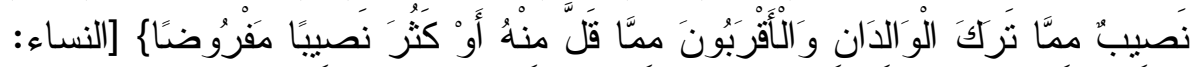

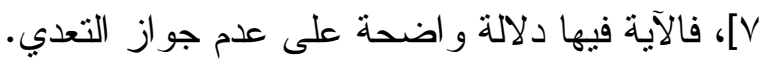

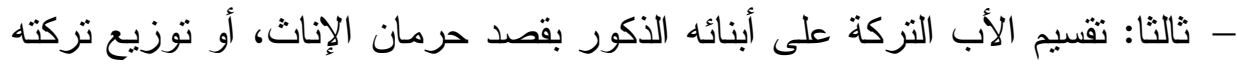

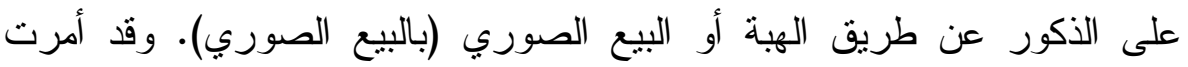

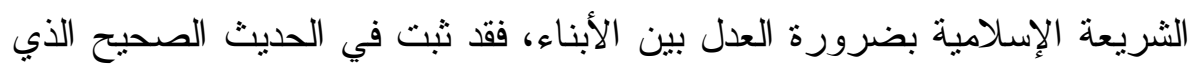

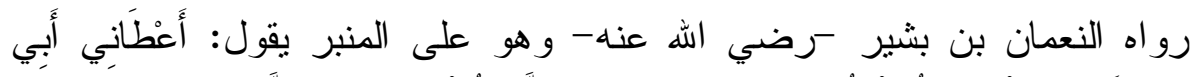

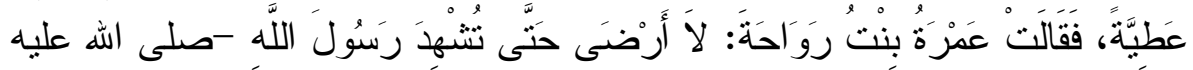

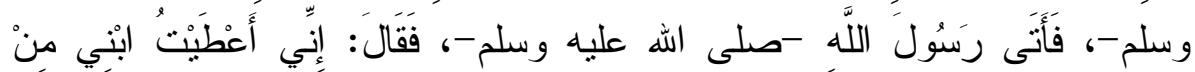

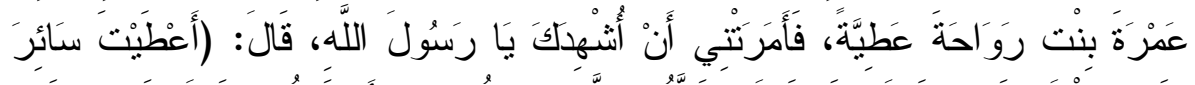

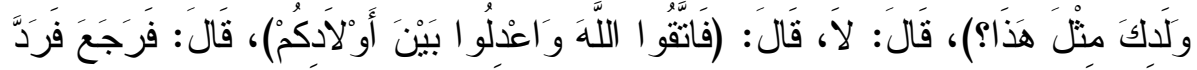

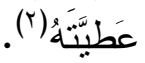
- ر رابعًا: ادعاء كل واحد من الإخوة أنه الوصي على إخوته بقصد الاستيلاء على

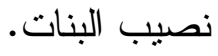
- خامسًا: تأجيل تقسيم التركة جييًا بعد جيل حتى نتداخل الحقوق وتُسىى.

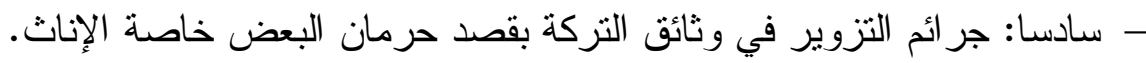

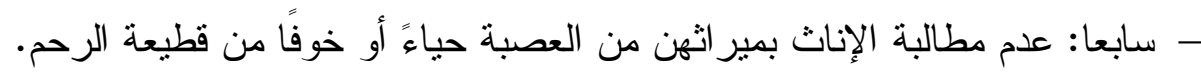

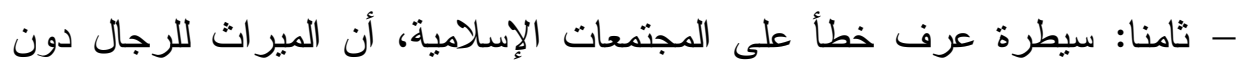

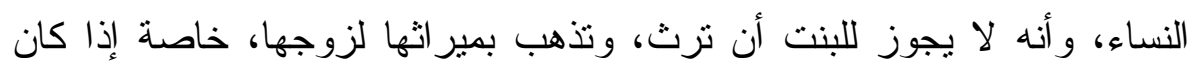

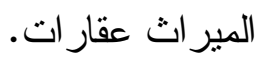


- تاسعا: سيطرة الأم ووقوفها بجانب العصبات؛ لاعتقادها التام أن الميراث للعصبات فقط دون النساء، وأن المر أة يكفيها جهاز زو اجها بهان فقط من بيت أبهاء أبيها. هذه أهم مخالفات العصبات في المجتمع المسلم.

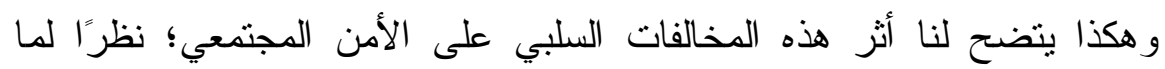

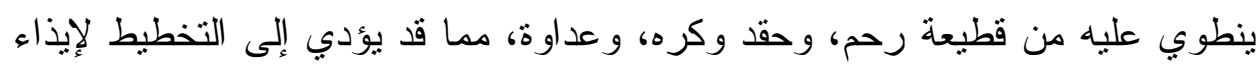

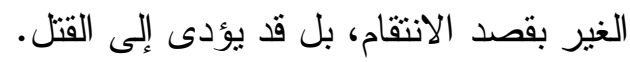
المبحث الثاني: الآثثار المترتبة على المخالفات المنتشرة في ميرداث المئ العصبات وكيفية معالجتها.

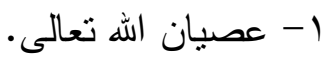

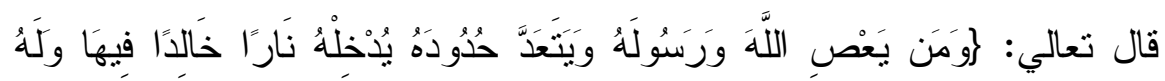

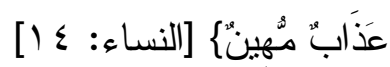
r- الاسنيلاء على حق الغير ظلمًا و عدو انًَا.

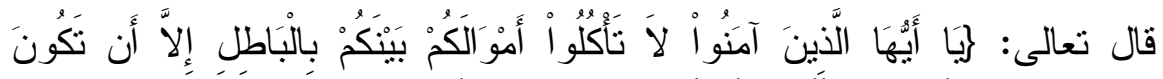

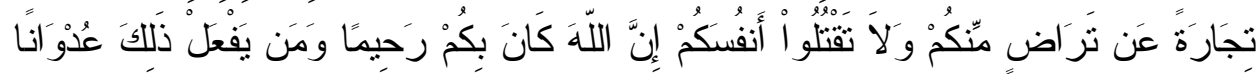

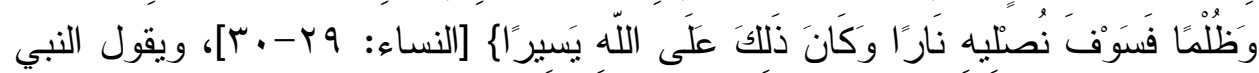

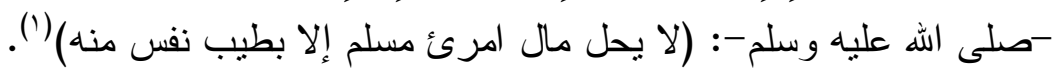

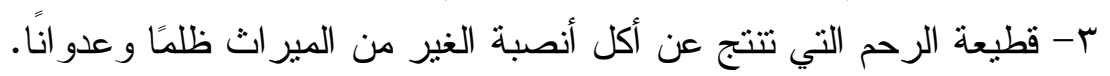

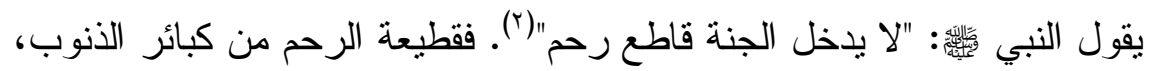
ومن أسباب الحرمان من الجنة إلا إذا عفا الله عن صاحبها. ع- تعرض الإناث اللاتي أكل العصبات أمو الهن للفقر الثنديد، خاصة إذان إذا لم يكن لهن عائل. ه- حصول الحقد و الكر اهية و العداوة بين الأقارب و استمر ارها لسنو ات عديدة.

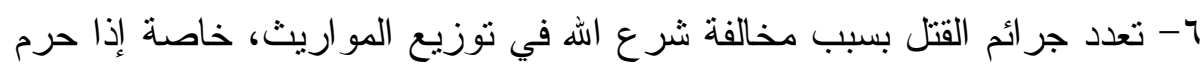
الأب بعض أبنائه من المير اث لأي سبب من الأسباب. 
عندما يتعلق الأمر بالمير اث يظهر كل شخص على حقيقته، وتتقطع حبال الود،

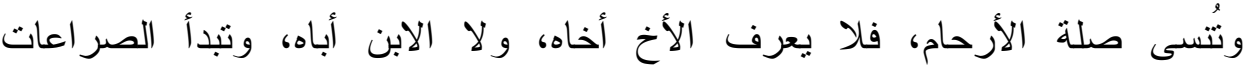

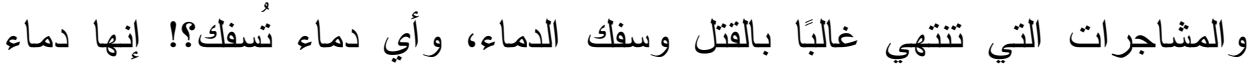

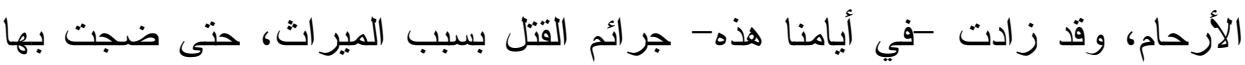

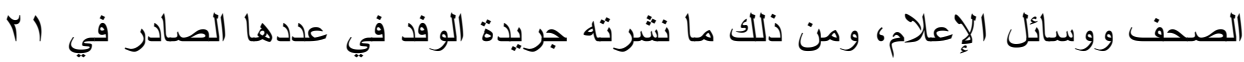

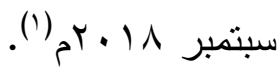
علاج هذه المخالفات:

1- عمل الدعاة على تو عية الناس ومعرفة الحقوق الثابتة في المير اث.

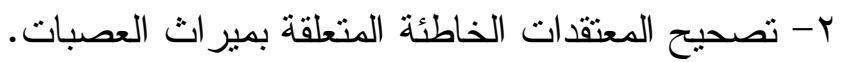
r- توجيه الأبناء إلى ضرورة عدم تفضيل بعض الأبناء على بعض بشيء من

$$
\text { المير اث. }
$$

ع - توجيه النساء إلى ضرورة المطالبة بحقهن في المير اث و عدم التنازل عنه حياء

$$
\text { أو إكر اها أو خوفا. }
$$

0- توجيه العصبات بضرورة رد الحقوق إلى أهلها وحرمة أكلها. 


\section{الخاتمة}

الحمد لله الذي بنعمته تتم الصالحات.

فبعد انتهاء البحث المختصر عن مير اث العصبات نلخص الحقائق التالية:

أو لا: المير اث حدده الله تعالى و لا يجوز مخالفته بالزيادة أو النقصان.

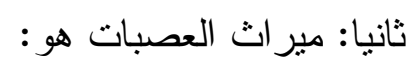

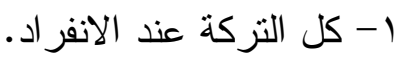

1- لا شيء لهم، إذا استغرق أصحاب الفروض التُر التركات.

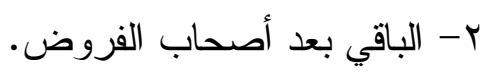

ثالثا: الترجيح بين العصبات يكون بالجهة أو الدرجة أو بقرب القرابة، ويكون ذلك بين

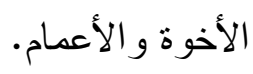

رابعا: توزيع الميراث تبعًا لثرع الله تعالى يحمى المجتمعات من الجرائم، وقطيعة

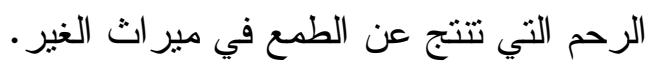
التوصيات:

أو لا: ضرورة توجيه العصبات إلى رد الحقوق إلى أصحابها. ثانيا: حماية حقوق الورثنة خاصة النساء و الأطفال.

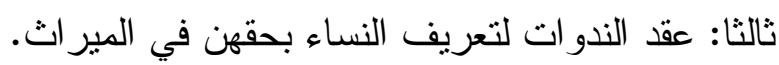
رابعا: مو اجهة الأعر اف التي تخالف شرع الله. 


\section{قائمة المصادر والمر اجع}

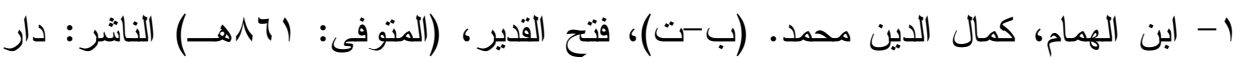

الفكر

r- ابن رشد، أبو الوليد محمد. (ب-ت)، بداية المجتهد ونهاية المقتصد. الطبعة: بدون طبعة. الناثر : دار الحديث - القاهرة.

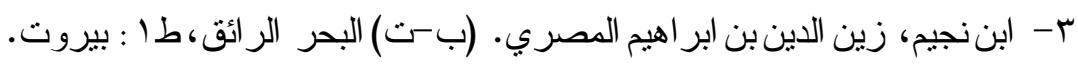

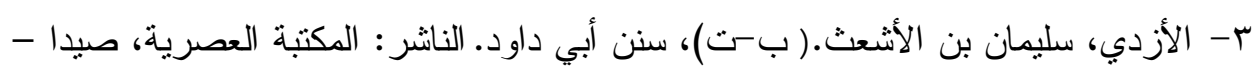
بيروت.

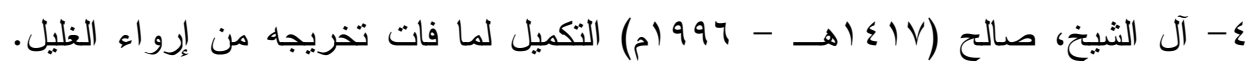
الناشر : دار العاصمة للنشر و التوزيع، الرياض الطبعة: الأولى.

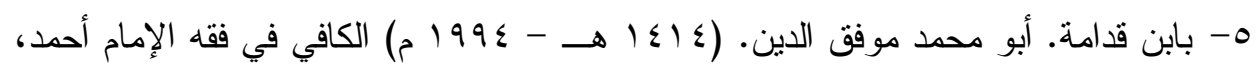
الطبعة: الأولى، الناشر : دار الكتب العلمية. צ- البخاري، محمد بن إسماعيل، ( . .ـ1 هـ)، صحيح البخاري. ط: (ب؛ القاهرة: المكتبة السلفية.

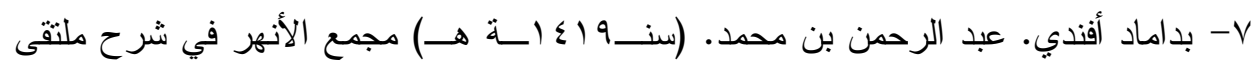

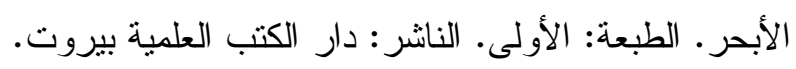

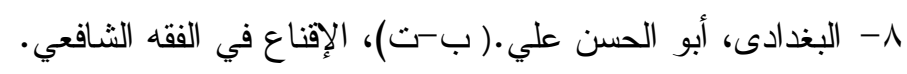

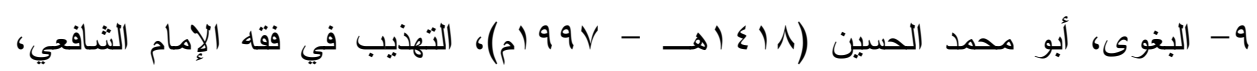
الطبعة: الأولى، الناشر: دار الكتب العلمية. • 1- البهوتي، منصور بن يونس (•r؟ ())، كثاف القناع طبعة وزارة العدل (د- ط).

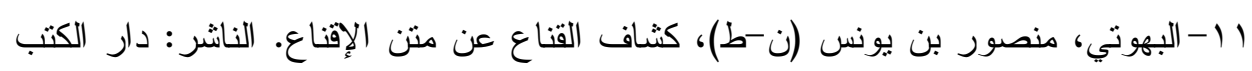
العلمية.

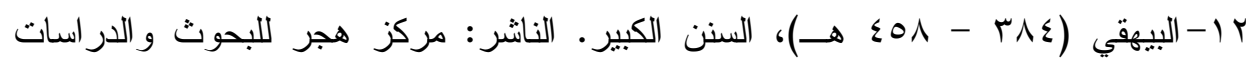
العربية والإسلامية (الدكتور : عبد السند حسن يمامة).

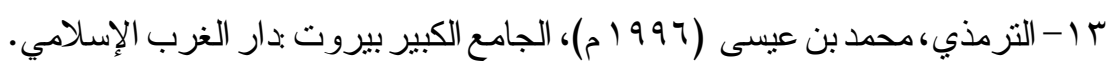

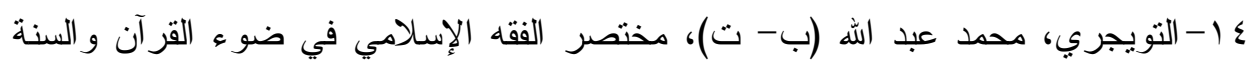
دار أصداء المجتمع، المملكة العربية السعودية ط: الحادية عشرة. الهدية 
ها-الجوزى، ابن القيم الجوزية (بr\{ (هـ)، أعلام الموقعين، ن، دار ابن الجوزي، ط الأولى. - طولى

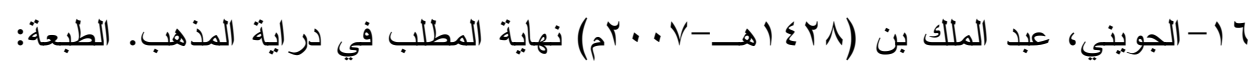

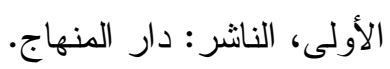

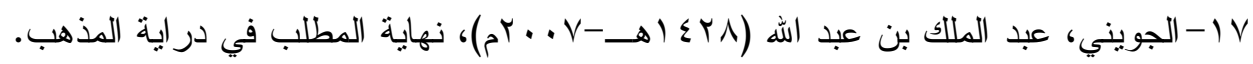
الطبعة: الأولى، الناشر : دار المنهاج.

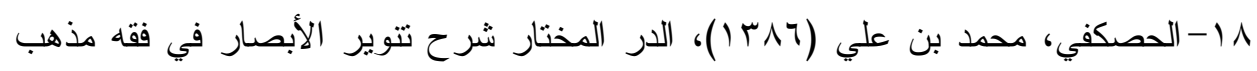
الإمام أبي حنيفة. دار الفكر • بيروت.

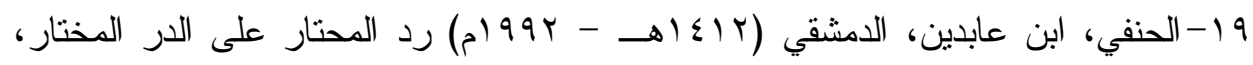

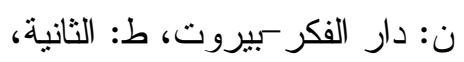

• ب- الخرشي، محمد بن عبد الله (د- ت)، مختصر خليل للخرشي(د-ط) دار الفكر للطباعة بيروت.

اب-الدمشقي، بن محمد بن عبيد (1 بـ هــ)، كتاب الأجوبة للشيخ أبي مسعود عما أثنكل الثيخ الدارقطني على صحيح مسلم بن الحجاج أبي مسعود الامشقي الناشر : دار إحياء النز اث العربي - بيروت. r r-الرازي (VI97)، مختار الصحاح. دار الكتاب العربي - بيروت - لبنان - الطبعة الأولى.

بr - الرحبياني، مصطفى بن سعد مطالب (10 الاولى (هـ - ـ99 (م)، أولي النهى في شرح غاية

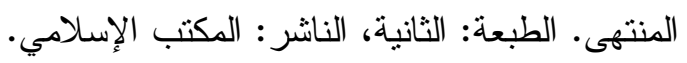

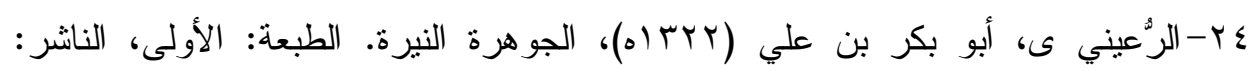
المطبعة الخيرية.

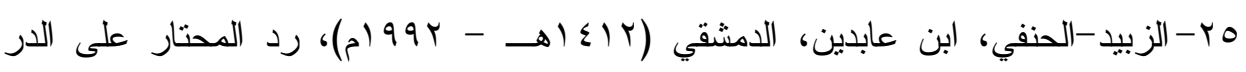
المختار، ن: دار الفكر -بيروت، ط: النئ الثانية.

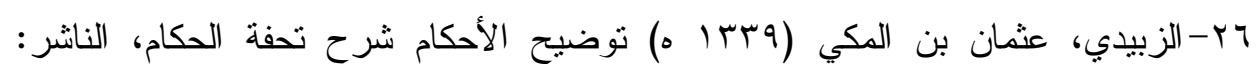
الطبعة: الأولى، المطبعة التونسية.

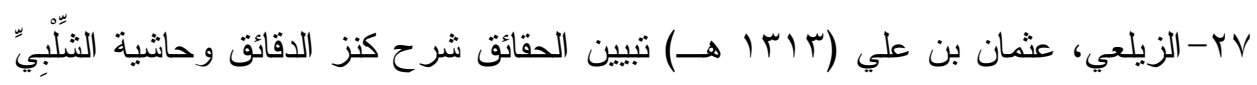

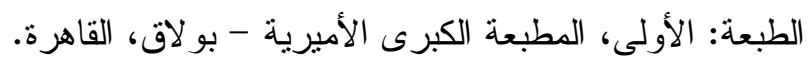




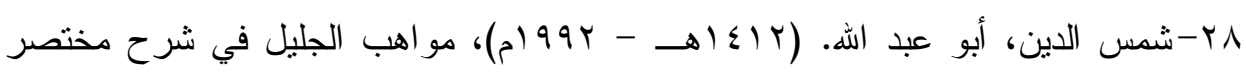
خليل. الطبعة: الثالثة، الناشر : دار الفكر .

و ج- الثهرستاتي، محمد بن عبد الكريم ( ب-ت) الملل و النحل، ط در ا المعرفة، بيروت.

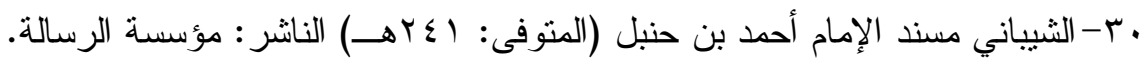
ع - الثيباني، (ب-ت)، مسند الإمام أحمد بن حنبل. الناشر : مؤسسة الرسالة.

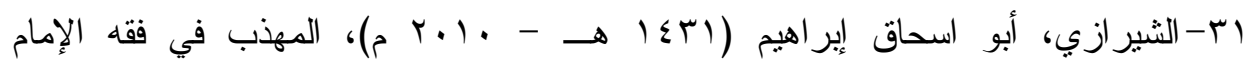
الثافعي، ن: دار الفكر بيروت.

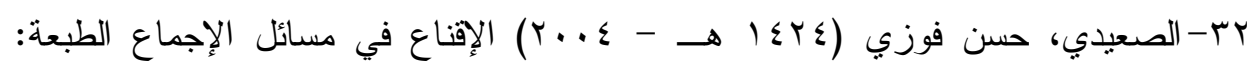

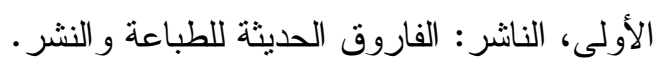

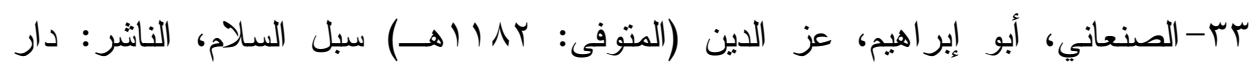

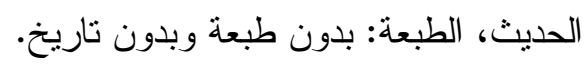
ع ب- العسقلاني :أحمد بن عمير بن حجر (ب- ت ت) فتح الباري بشر ح صحيح البخاري. تصحيح

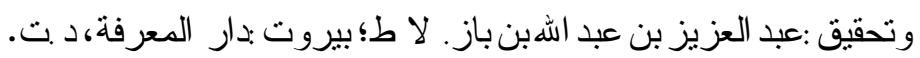

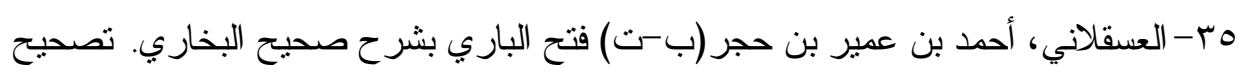

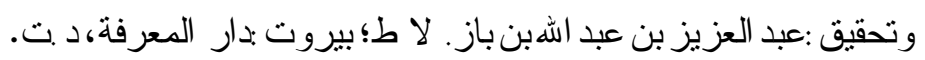

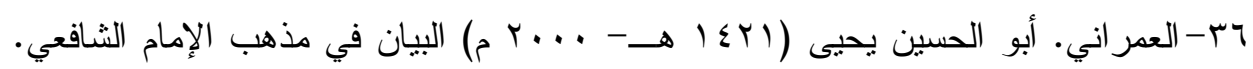

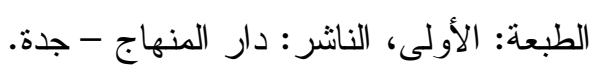

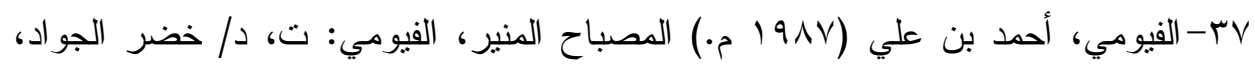
لا. ط؛ بيروت: مكتبة لبنان.

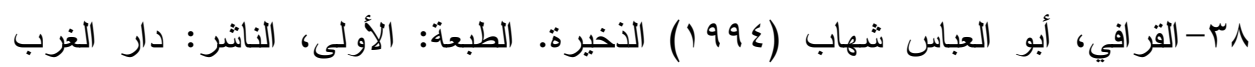

$$
\text { الإسلامي - بيروت. الفري، }
$$

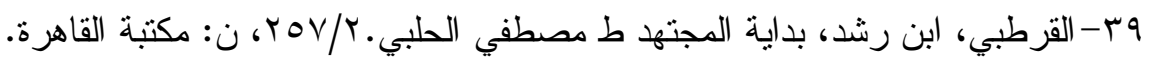

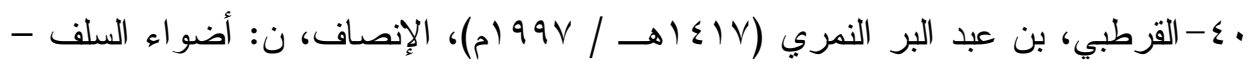

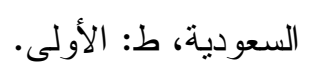

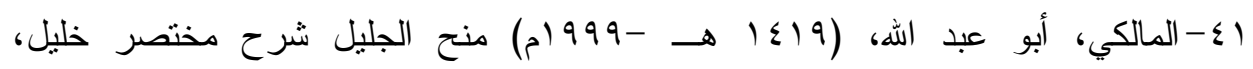
ط: الأولى، الناشر : دار الفكر - بيروت طا: بدون طبعة، ن: دار الكتب العلمية، 
بـ-الماوردي، أبو الحسن علي بن محد الحاوي (19 1 هـ -1999 م) الحاوي الكبير.

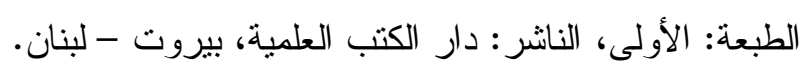

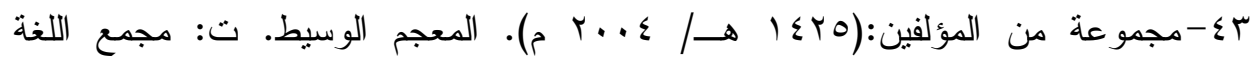

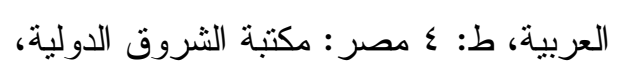

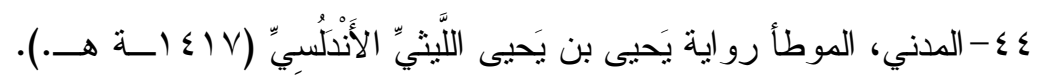

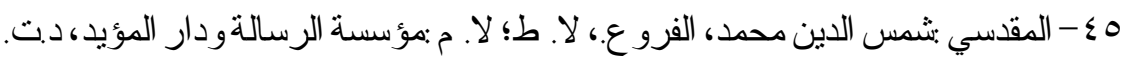

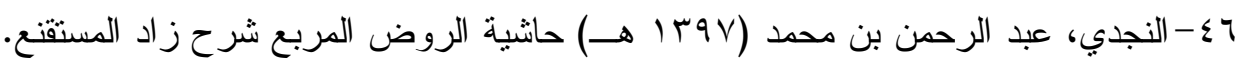

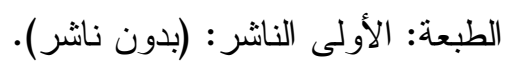

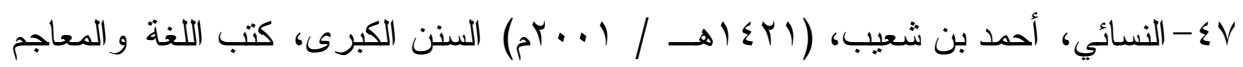

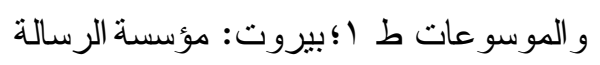

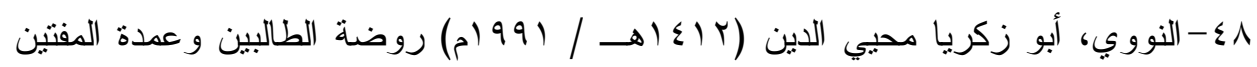

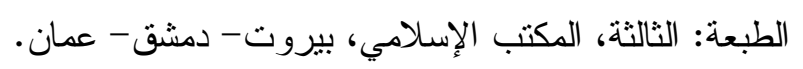

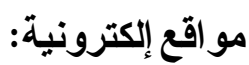

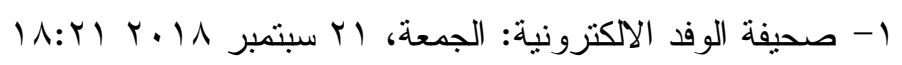

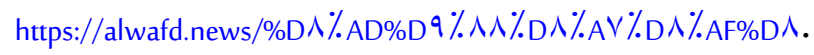

\section{List of sources and references}

1- A group of authors: $1 \leqslant$ ro AH / r. \& $\varepsilon$ CE The Intermediate Lexicon. T: Academy of the Arabic Language, $\{$ th Edition, Egypt: Al Shorouk International Library،

r- Al-Amrani. Abu Al-Hussain Yahya I $\{r$ AH - r... AD) The statement in the school of Imam al-Shafi'i. Edition: First, Publisher: Dar Al-Minhaj - Jeddah.

r- Al-Asqalani: Ahmad bin Umair bin Hajar (b-c) Fath Al-Bari, explained by Sahih Al-Bukhari. Correction and investigation: Abdul Aziz bin Abdullah bin Baz. No i; Beirut: House of Knowledge, Dr. T.

¿- Al-Asqalani: Ahmad bin Umair bin Hajar, (b- c) Fath al-Bari with the commentary of Sahih al-Bukhari. Correction and investigation: Abdul Aziz bin Abdullah bin Baz. No i; Beirut: House of Knowledge, Dr. T

-. Al-Azdi. Suleiman bin Al-Ash'ath Sunan Abi Dawood, (b-t) Publisher: Modern Library, Saida - Beirut. 
7- Al-Baghawi, Abu Muhammad Al-Hussein ( I 1 ) AH - 199 У AD) Al-Tahdheeb fi Al-Imam Al-Shafi'i Jurisprudence, First Edition, Publisher: Dar Al-Kutub AlIlmiyya

V- Al-Baghdadi, Abu al-Hasan Ali. (B-c)) Persuasion in Shafi'i jurisprudence.

A- Al-Bahouti, Mansour Bin Yunis ( $\leqslant$ r $\cdot$ ), the Scouts of Al-Qanaa, edition of the Ministry of Justice

9- Al-Bahouti, Mansour Bin Yunis (n-i), the scouts of the mask on the body of persuasion. Publisher: House of Scientific Books.

1.- Al-Bayhaqi Al-Sunan Al-Kabeer. ( $\wedge \wedge \varepsilon$ - $\{0 \wedge$ AH). Publisher: Hajar Center for Research and Arab and Islamic Studies (Dr. Abdel Sanad Hassan Yamama(

1)- Al-Bukhari, Muhammad bin Ismail ( $\{\ldots$ AH) Sahih Al-Bukhari. I: 1; Cairo: The Salafist Library.

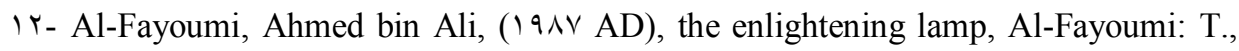
Dr. Khader Al-Jawad, no. I; Beirut: Lebanon Library.

Ir-Al-Hanafi, Ibn Abdin, Al-Dimashqi (I \&lr A.H. - I99r A.D.), the confused response to Al-Durr Al-Mukhtar, n: Dar Al-Fikr - Beirut, i: the second

I $\leqslant-$ Al-Hanafi, Ibn Abdin, Al-Dimashqi ( $\leqslant 1$ r A.H. - 199 r A.D.), the confused response to Al-Durr Al-Mukhtar, n: Dar Al-Fikr - Beirut, i: the second

10- Al-Hanafi, Ibn Abdin, Damascene ( $1 \leqslant 1$ r A.H. - 199 r A.D.), the confused response to Al-Durr Al-Mukhtar, n: Dar Al-Fikr - Beirut, i: the second،

17- Al-Hasakfi, Muhammad Bin Ali ( 1 rᄉ Enlightenment of Sights on the Jurisprudence of Imam Abu Hanifa's doctrine. Thought House. Beirut.

IV-Al-Jawzi, Ibn Al-Qayyim Al-Jawziyyah ( $(\leqslant r r$ AH), The Notables of the Two Signatories, N, Dar Ibn Al-Jawzi, First I.

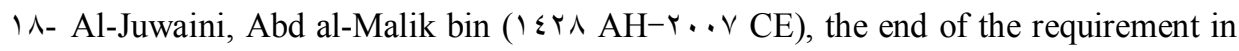
the knowledge of the doctrine. First edition, publisher: Dar Al Minhaj.

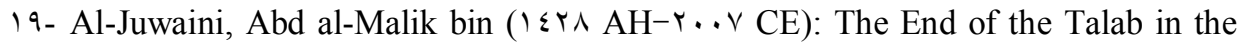
Familiarization of the School Edition: First, Publisher: Dar Al Minhaj. 
r.- Al-Khurshi. Muhammad ibn Abdullah (d- c) abbreviated Khalil al-Kharshi (d-i) Dar al-Fikr for Printing - Beirut.

Y - Al-Madani, Al-Muwatta, the narration of Yahya bin Yahya al-Laithi al-Andalusi ( I IV AH).

rr-Al-Malki, Abu Abdullah, (।乏।9 AH -1999), Al-Jalil granting the explanation of Mukhtasar Khalil, i: first, publisher: Dar al-Fikr - Beirut i: without edition, n: Dar al-Kutub al-Ilmiyya،

rr- Al-Maqdisi: Shams al-Din Muhammad, branches., No. I; No. M: Al-Risala Foundation and Dar Al-Moayad, dt.

r \&- Al-Maqdisi: Shams al-Din Muhammad, branches., No. I; No. M: Al-Risala Foundation and Dar Al-Moayad, dt.

ro- Al-Mawardi, Abu al-Hasan Ali bin Muhammad al-Hawi ( 1 19 AH - 1999 CE) alHawi al-Kabir. Edition: First Edition, Publisher: Dar Al-Kutub Al-Ilmiya, Beirut Lebanon.

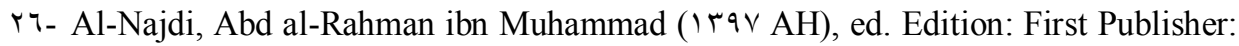
(without publisher).

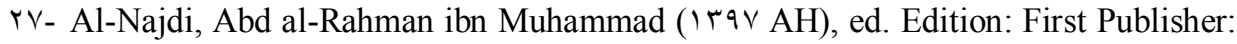
(without publisher).

r^- Al-Nawawi, Abu Zakaria Muhyiddin ( $1 \leqslant 1$ T AH / 199 । AD) Kindergarten of the Talibin and the Mayor of the Muftis

rq- Al-Nawawi, Abu Zakaria Muhyiddin ( $1 \leqslant 1$ AH / 199 । AD) Kindergarten of the Talibin and the Mayor of the Muftis

r.- Al-Qarafi Abu Al-Abbas Shihab, (। 99 ) Al-Ammunition. Edition: First, Publisher: Dar Al-Gharb Al-Islami - Beirut.

५ - Al-Qurtubi, A Ibn Rushd: Bidaya al-Mujtahid, Mustafa al-Halabi. r/rov, N: Cairo Library.

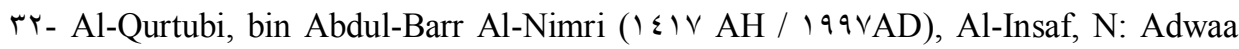
Al-Salaf - Saudi Arabia, First Edition.

rr- Al-Rahbiani, Mustafa bin Saad Muttalib (1 10 AH - 199 CE) was the first to explain the purpose of the end. Edition: Second, Publisher: The Islamic Office. 
rะ- Al-Raini, Abu Bakr bin Ali (Irr A.H.) - The Enlightened Jewel. Edition: First, Publisher: Charity Press.

ro- Al-Razi, Mukhtar As-Sahih (19тv) House, Arab Book - Beirut - Lebanon - First Edition.

ฯ - Al-Saidi, Hassan Fawzi ( $\leq\ulcorner\leq A H-r \ldots \varepsilon)$ Al-Iqna 'in matters of consensus, first edition،

r - Al-San`ani, Subul Al-Salam Abu Ibrahim, Ezz Al-Din (died: 11 Ar AH) Publisher: Dar Al-Hadith, Edition: without edition and without date.

ґ^- Al-Shahristati, Muhammad ibn Abd al-Karim, (,) b-c)) Al-Mullal Wal-Nahal, Dar Al-Maarifa, Beirut.

५ - Al-Shaibani Musnad of Imam Ahmad bin Hanbal. (B-T) Publisher: The Message Foundation.

s.- Al-Sheikh, Saleh ( $1 \leqslant 1 \vee$ AH - 1997) to complete what he had graduated from Irrwa al-Ghaleel. Publisher: Dar Al Asimah Publishing and Distribution, Riyadh First Edition, M.

§)-Al-Shirazi, Abu Ishaq Ibrahim (। $\leqslant$ I A.H. - Y.।. A.D.), Al-Muhadhab in the jurisprudence of Imam Al-Shafi `i, n: Dar Al-Fikr Beirut

¿r-Al-Tirmidhi, Muhammad bin Isa (1997 AD) The Great Mosque, Beirut: Dar AlGharb Al-Islami.

¿r-Al-Tuwaijri, Muhammad Abdullah (b- c), the Compendium of Islamic Jurisprudence in the Light of the Qur'an and Sunnah, House of Society Echoes, Kingdom of Saudi Arabia I: Eleven.،

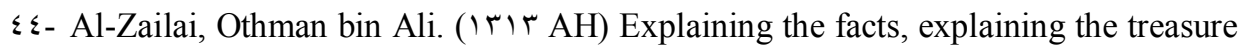
of the minutes and Haashiyat al-Shalabi, Ist edition, The Great Amiriya Press Bulaq, Cairo

ะo-Al-Zubaidi, Othman bin Al-Makki (I r Explanation of Tuhfat Al-Hakam, Publisher: Edition: First, The Tunisian Press.

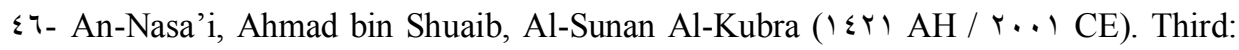
Language books, dictionaries, and encyclopedias i); Beirut: The Message Foundation 
¿V-An-Nasa'i, Ahmad bin Shuaib, Al-Sunan Al-Kubra ( $\mid \leqslant Y)$ AH / Y . I CE). Third: Language books, dictionaries, and encyclopedias i); Beirut: The Message Foundation

§^- Damad Effendi. Abdul Rahman bin Mohammed. (Year 1 19 AH) Al-Anhar Complex explaining the Al-Bahr Junction. Edition: first. Publisher: Dar Al-Kutub Al-Ilmiyya Beirut.

¿१- Damascene Y). Ibn Muhammad Ibn Ubayd. («• AH) The Book of Answers by Sheikh Abi Masoud on what Shaykh al-Daraqutni formed on Sahih Muslim Ibn alHajjaj Abi Masoud al-Dimashqi Publisher: Dar Revival of Arab Heritage - Beirut

๑.- Edition: First, Publisher: House of Scientific Books.

0) - Edition: First, Publisher: House of Scientific Books.

or- Edition: The Third, The Islamic Office, Beirut - Damascus - Amman.

or- Edition: The Third, The Islamic Office, Beirut - Damascus - Amman.

๑ะ- Ibn al-Hamam, Kamal al-Din Muhammad (b-c) Fath al-Qadeer, (deceased: ^ฯ) AH) Publisher: Dar al-Fikr

๑o- Ibn Najim: Zain Al-Din Ibn Ibrahim Al-Masry, (b-c) the clear sea, i: I Beirut.

07- Ibn Qudamah. Abu Muhammad Muwaffaq al-Din. ( $\leqslant 1 \leqslant$ AH - 199 $\leq$ AD) Al-Kafi in the jurisprudence of Imam Ahmad

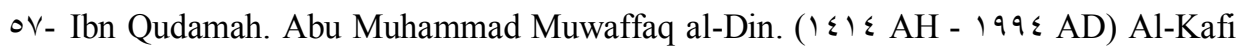
in the jurisprudence of Imam Ahmad

o^- Ibn Rushd. Abu Al-Walid Muhammad (b-c) The beginning of the mujtahid and the end of the economy. Edition: without edition.

๑१- Publisher: Al-Farouq Modern Printing and Publishing.

7.- Publisher: Dar Al Hadith - Cairo

7) - Shaibani Musnad of Imam Ahmad bin Hanbal. (Deceased: r 1 A.H.) Publisher: The Resala Foundation

rr- The author: Bin Idris Al-Bahouti (d-i.)(

\section{Websites:}

1- Al-Wafd Electronic Newspaper: Friday, $\uparrow \mid$ September $r \cdot 1 \wedge \mid \wedge: \curlyvee$ ।

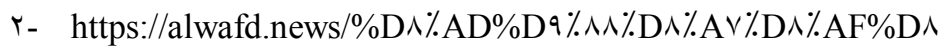

